\title{
大学生创新创业教育实践的相关分析
}

\section{Analysis on the practice of innovation and entrepreneurship education for College Students}

\author{
罗清 \\ Qing Luo \\ 宁德师范学院 中国·福建 宁德 352100 \\ ningde normal university, Ningde, Fujian, 352100, China
}

\begin{abstract}
摘 要: 在现代化社会的发展中, 大学生创业潮日益兴起, 大学生创业已得到社会各界的高度重视, 很多高校都针对在校 大学生开展了相关的创新创业教育活动, 鼓励、支持大学生自主创新, 为了更好地开展大学生创新创业教育实践活动, 高 校需要从人才培养、人才价值理念、教学方法等方面予以创新, 引导大学积极参与创新创业教育实践活动中, 以适应现代 社会的发展，文章主要针对大学生创新创业教育实践的相关内容进行了分析。
\end{abstract}

\begin{abstract}
College Students' entrepreneurship is rising day by day, and college students' entrepreneurship has been highly valued by all walks of life. Many colleges and universities have carried out relevant innovation and entrepreneurship education activities for college students to encourage and support their independent innovation. In order to better carry out the practical activities of College Students' innovation and entrepreneurship education, colleges and universities need to cultivate talents and talents In order to adapt to the development of modern society, this paper mainly analyzes the relevant contents of innovation and entrepreneurship education practice for college students.
\end{abstract}

关键词: 大学生; 创新创业; 教育实践

Keywords: college students; innovation and entrepreneurship; education practice

DOI: $10.36012 /$ sde.v3i1.2872

\section{1 引言}

在新时期的高校教育教学中, 创新创业教育作为一种现 代化教育理念、教学模式, 大学创新创业教育实践教学体系 将创新教育体系、创业教育体系、专业教育体系进行了有效 融合, 培养学生的创新精神、创新意识、创业能力, 为大学 生的稳定发展提供支持。为了适应现代社会的发展, 高校需 要建立完善的创新创业教育制度, 为大学生创新创业教育实 践提供保障。基于此, 文章阐述了创新创业教育的相关内容, 分析了大学生创新创业教育实践现状，总结了相应的策略。

\section{2 创新创业教育概述}

创新创业教育内涵主要根据面临对象、侧重点的差异, 给予相应的解释 ${ }^{[1]}$ 。首先, 从理论层次进行分析, 创新创业 教育是指贯穿于创新与创业教育, 满足社会经济发展需求, 以满足高校人才培养、科学研究、社会服务功能要求的教育 理念、教育体系。其次, 从实践操作角度进行分析, 创新创
业教育指的是将学生专业教育创新、创业教育进行融合, 在 创新教育理念基础上, 针对人才培养模式、教学内容、教学 方法进行优化, 提高学生的创新创业意识, 培养学生的社会 责任感, 为学生的全面发展提供支持。最后, 从基础价值取 向角度进行分析, 创新创业教育重点是培养优秀人才, 针对 创新创业人才予以培养、储备。

\section{3 大学生创新创业教育实践现状}

\section{1 创新创业教育体系有待完善}

随着社会的快速发展, “双创” 已成为高等教育教学的 热门话题, 很多高校、教育培训机构都根据大学生创新创业 教育进行了不同角度的分析, 在制定高校创新创业教育体系 过程中，主要从基础设备设施、资金政策、利益相关制度、 理论实践课程体系、产学研合作等方面, 构建了初步的创新 创业教育体系, 但实践操作引导不够, 相关体系还需要进一 步完善, 很难形成完善的创新创业教育体系, 无法将其全面 
实施到各项工作中, 后期使用过程中也会遇到很多难题, 很 难培养出创新创业的复合型人才。

\section{2 创新创业教育课程设置不合理}

高校在开展创新创业教育活动的过程中, 需要借助课程 体系进行, 教育部门需要设置科学、合理的课程体系。现阶段, 高校师生的 “双创” 理念日益深人, 很多高校都开始针对人 才培养方案课程体系进行调整, 通过构建以创新创业人才为 目标的课程体系, 还有很多高校设立了专业的创业学院, 并 申请了各级创业中心。但是, 在实际运行过程中, 很多高校 简单地将创新创业课程作为培养方案的部分内容, 或者将过 去课程名称进行替换, 有些高校错误认为扩大实践教学内容 就能够实现创新创业教育目标, 还有很多学校会从整体课程 体系进行结构改变, 但受实践的影响, 课程不够科学、合理, 与过去相比取得了很大的成果, 但很难从根本上提升大学生 创新创业教育水平, 无法实现创新创业优秀人才的培养目标。

\section{3 创新创业观念和思维有待更新}

在社会的发展中, 我国各个行业都鼓励大学生创新创 业, 在一定程度上激发了大学生的创新、创业意识, 教育部 门、行业协会等开展了大学生创新创业相关的挑战杯、竞赛 活动, 并设立了大学生创新创业项目, 通过实行全国巡讲方 式, 引导大学生理解创新创业的内容, 并采取相关策略向大 学生提供创新创业相关的资金、政策、荣誉作为支持, 促使 高校在校内、社会开展了创新创业相关的活动, 但这些活动 的主要目标是短期收益, 一般在项目、比赛活动结束后, 未 针对项目进行跟踪、深度开发、合作, 导致学生得到奖励、 教师得到荣誉后, 学生和教师会继续按照原来的方式进行学 习、教学, 甚至会投入到其他项目、竞赛活动中 ${ }^{[2]}$ 。因此, 高校通过开展以科技竞赛推动大学生创新实践项目, 激发了 教师、学生的参与积极性, 但创新创业能力培养制度不够完 善, 导致大学创新观念、逻辑思维、逆向思维培养不够深入, 直接影响着大学生创新创业教育实践的有效性。

\section{4 大学生创新创业教育实践策略}

\section{1 建立完善的创新创业教育实践体系}

首先, 建立校内实践平台。高校需要建立大学生创新 创业模拟实验平台, 引导大学生学习更多专业知识, 通过模 拟实训软件, 使其加深对专业技能的掌握, 充分利用自身优 势学习更多的知识。其次, 建立内外实践项目。高校需要通
过第二课堂活动, 针对大学生创建创新创业项目, 并以创新 创业竞赛、专题交流会等方式, 积极开展相关活动, 建设良 好的创新创业环境, 激发大学生的创新创业意识, 引导大学 生制定创新创业计划, 促进创业活动的顺利开展。

\section{2 建设高素质的创新创业教师队伍}

在高校教育教学过程中, 相关部门需要针对优秀的教 师资源进行整合、优化, 强化创新创业教育专业教师培养力 度, 鼓励教师兼职企业聘用, 根据实际情况建立完善的考核 制度, 实现高校人才、教师资源的充分利用。为了建设高素 质的创新创业指导教师队伍, 高校需要引进更多具备专业特 长、兴趣的教师, 以及具备创业经验的企业人才, 建设理论、 实践结合的优秀教师队伍。另外, 政府部门、社会各界需要 向创新创业投入更多的政策、资金作为支持，高校也要定期 组织相应的培训活动、交流会议, 提高教师队伍的综合素质, 为学生提供实践机会。

\section{3 创办大学生创业孵化园}

大学生创业捊化园为学生创新创业实践提供了平台, 为 创业实践提供了一定的条件支持, 可以针对创新创业大学生 予以指导, 为其提供更多实践的机会。首先, 在建设大学生 孵化园的过程中, 需要建设全面的学习计划, 分阶段、分级 开展实践活动, 并根据高校实际情况, 合理设置睬化园场地, 以满足更多创业粰化项目、创业企业的建设要求。其次, 高 校需要完善大学生创业捊化园的相关设施, 如水电网、办公 工具、计算机软件等, 为教师指导、服务提供保障。最后, 在大学生创业睬化园管理过程中, 高校需要安排专业人员做 好各项管理工作, 还需要建设专业性的创新创业项目管理队 伍, 主要成员有教师、企业家、专家等, 为创业项目立项、 审批、项目运行予以指导、监督。最后, 建设高质量的创 业项目指导队伍, 针对大学生进行创业指导、帮助, 还需要 定期开展相关的研讨会, 及时分析大学生的创业项目实施情 况、问题等, 积极开展经验交流活动, 解决大学生创业过程 中遇到的难题, 提高大学生创新创业教育实践的整体水平。

\section{5 结束语}

综上所述, 在新时期的高校教育教学过程中, 创新创 业教育的重要性日益突显出来, 现已成为社会培养创新创业 人才的关键方式, 推动大学生未来的良好发展 ${ }^{[3]}$ 。因此, 高

(下转第 96 页) 
金量和工艺水平。其次，在实训过程当中可以基于项目的引 领，通过公众号、APP 等多种手段，开设综合性设计师等 前沿的项目, 以此为学生的实践提供基础。

\section{3 实施 $3+x$ 创新训练模式}

在新形势下为了更好地推动创新在日常教学当中的融 合, 高校可以深入实施 “ $3+\mathrm{x}$ ”创新训练模式。首先, 要以 任务驱动学生, 让学生的主体性得到发挥, 进而实施教师指 导的 “ $3+x$ ” 及基础项目和项目叙事模式, 这种教学模式能 够提高工程专业学生的专业综合能力和创新能力以及就业 能力。其中, 基础训练就是一些基本技能的训练, 例如, 在 网上教师通过安全教育的学习之后, 可以通过一些实训的影 片以慕课、微课的形式让学生观摩, 以此激发学生的兴趣和 好奇心, 进而加以培养学生的创新思维, 引领学生完成基础 训练。其次, 在此项目完成之后, 教师又可以让学生进行加 工方法工艺设计创新, 创作作品设计的基本训练, 让学生以 项目为基准, 按时间、内容的程度不同, 设计不同的方案, 确定不同的选择内容, 突出自主研发式学习, 让学生通过项 目延续地完成, 在工程环境当中解决实际问题, 以此让学生 亲身体验, 以此推动生产环节的实践化。

\section{4 打造双师型师资队伍}

在新的理念下, 要想真正地提高工程专业人才的培养, 必须要加大对教师的培养, 教师既是教育工作的推行者又是 教育工作者。而教师作为学生提高综合实践能力的引导者, 如此教师水平的高低决定了工程训练实践课程开设的质量。 由此高校应该重视师资团队的建设，保证实践教学的质量。 有素质的教师团队是高校工程训练实践课程健康发展的重 要因素, 也是保证学生能力得到提升的关键。由此学校应该 注重培养教师的多元化发展, 为教师建立师资培训工作站, 推动教师团队的建设。所谓促进教师的多元化发展就是夯实 教师的知识基础, 确保教师知识专业化, 为实现教师由理论
型转向实践型做基础。其次, 要培养教师的实践能力, 教师 在拥有丰富理论知识的基础之上，才能够将知识进行实践。 教师的实践精神才能够有效地建立起企业和学校之间的联系, 进而提高学生的从业素质。最后, 应该培养教师的工作能力, 教师只有知道如何更好地从事教育工作, 如何将自己的理论知 识和实践操作运用到实际教学当中, 才能够推动学校工程训 练实践课程的发展。比如, 高校可以安排理论知识、实践知 识较为丰富的专业教师进入企业，进行实战演练。让教师在 企业当中承担相应的工作任务，让教师在实践当中积累经验。

\section{5 建立灵活多样共享机制}

在新形势下的新工科训练模式, 应该以学生为中心转 变运营机制, 将实验室模式转变为企业模式, 最终发展为工 程图书馆模式, 在完善现有实践教学的基础之上, 开展企业 模拟项目教学, 让学生能够走入企业去了解产品的研发过程 和生产过程, 由此能够熟练地操作其运营模式, 以此提高学 生的技术素养和管理能力。其次, 大众创业, 万众创新, 随 着计划的推进, 新工科建设就必须在工程图书馆模式建设和 推广之下, 通过各个基础训练创新开放工程服务校企合作中 心, 以此促进 3D 打印、设备租赁等项目的开展, 推进学生 智能能力和创新创业能力以及学生快速发展。

\section{4 结束语}

在新工科背景下, 现代工程训练体系的构建必须要基 于学生的实际情况, 注重高校本身的优势, 打造出属于本校 特色的, 能够反映出数字化、智能化的课程, 并且要基于时 代的引领, 培养出具有理论知识、实践能力、人文素养的新 时代工程师, 由此能够推动工程体系的改革, 同样也能够推 动高校工程体系课程的革新。

\section{参考文献}

[1] 刘建春. 面向新工科的工程训练实践课程体系构建 [J]. 教育现 代化, 2019, 6(87): 193-196.

的思考 [J]. 实验室科学, 2019, 22(02): 243-245.

[2] 张丽辉, 倪秀珍。“互联网 + ” 背景下大学生创新创业教育的 创新实践探索 [J]. 创新创业理论研究与实践, 2018, 1(06): 60-61.

[3] 张玉芳, 胡继连, 周玉䇛, 等. 实践教学在大学生创新创业教 育中功能发挥的研究与实践 [J]. 实验室科学, 2018(4): 230-233. 